\title{
Reflexões sobre um programa de pesquisa científica para a infraestrutura viária do Brasil
}

\author{
Reflections on a scientific research program for roadway infrastructure in \\ Brazil
}

Jorge Barbosa Soares ${ }^{1}$

1Universidade Federal do Ceará, Ceará - Brasil, jsoares@det.ufc.br

\section{Recebido:}

16 de setembro de 2019

Aceito para publicação:

17 de novembro de 2019

Publicado:

15 de dezembro de 2020

Editor de área:

Francisco Thiago Aragão

Palavras-chaves:

Ciência.

Pesquisa.

Pavimentos.

Infraestrutura.

\section{Keywords:}

Science.

Research.

Pavements.

Infrastructure.

DOI:10.14295/transportes.v28i5.2174

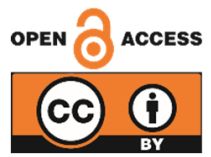

\begin{abstract}
RESUMO
Este artigo é motivado pela transição entre métodos de dimensionamento de pavimentos asfálticos no Brasil. Tem por objetivo facilitar um método de revisão do conhecimento útil a futuras atualizações. Apresenta-se uma análise sobre como a Ciência, com suas características que a tornam um paradigma da racionalidade frente a outras formas de compreensão e previsão, pode influenciar uma área estratégica, como a de infraestrutura viária. Um momento de transformações deste segmento no país, que envolve investimentos externos, concessões, privatizações, requer uma comunidade nacional equipada com o melhor conhecimento disponível e aguçada capacidade crítica. A Ciência tende a nos mover para mais perto do que se entende num dado momento como verdade e, na maior parte dos casos, o seu grau de aplicação de hoje tende a exceder métodos predecessores. A reflexão sobre Programas de Pesquisa Científica para infraestrutura viária é apenas um dos elementos para se construir uma área de fronteira no conhecimento acadêmico e na inovação de empresas e do poder público.
\end{abstract}

\begin{abstract}
This paper is motivated by the transition between asphaltic pavement design methods in Brazil. The objective is to facilitate a method for knowledge revision that can be useful for future updates. It is presented an analysis of how Science, with its characteristics that makes it a paradigm of rationality when compared to other forms of comprehension and prediction, can affect a strategic area such as roadway infrastructure. A transforming moment of the sector in Brazil, with international funding, concessions, privatizations, require a national technical and scientific community equipped with the best available knowledge and with critical ability. Science moves us towards to what is believed to be truth in a given moment. In most cases, its application today exceeds predecessor methods. The reflection about Scientific Research Programs for roadway infrastructure is only one element to build an area at the frontiers of knowledge in both academia and innovation for businesses and the public sector.
\end{abstract}

\section{INTRODUCÃO}

A motivação para o presente artigo surgiu da observação sobre o processo da transição, ainda em curso, entre métodos de dimensionamento de pavimentos asfálticos no Brasil, o que inclui a atualização de normas. 0 objetivo é facilitar um método sistemático de revisão do conhecimento, tomando como base e inspiração metodologias usualmente empregadas pela Ciência. Espera-se que o documento suscite reflexões que ajudem na autocorreção sempre necessária quando as observações detectam a necessidade de atualização do núcleo de saber existente em um dado momento. 0 tipo de discussão daqui decorrente poderá ter um efeito de curto prazo na atual transição entre métodos e ajudar em planejamentos para outras transições, que 
ocorrerão na medida do progresso do conhecimento. A expectativa é de que a comunidade científica, na sua pluralidade de visões, possa ter um papel cada vez mais cooperativo e que, em parceria com o governo e com a indústria, garanta que jamais se reproduza no país o retardamento que houve na atualização entre, por exemplo, os métodos de 1966/1981 (Souza, 1981) e outros mais recentes (Motta et al., 2018).

A engenharia viária possui complexidades não apenas na caracterização dos materiais, previsão das cargas (tráfego), efeito do clima e do tempo sobre a resposta estrutural do sistema de camadas, mas também na qualificação da infraestrutura física e de pessoal, além de dissintonia entre projeto e execução. 0 presente foco em questões científicas associadas ao setor não sugere que estas são as mais relevantes ou que eventualmente se transformarão em uso prático. 0 foco escolhido deveu-se à premissa de que a Ciência, pela sua capacidade de articulação de conhecimentos confiáveis e abertura ao debate, tem o potencial de ajudar no processo hoje vivenciado pela área de infraestrutura viária, cujo amadurecimento intelectual e a sofisticação de métodos e práticas ainda é incipiente, principalmente comparados a outras áreas mais básicas e mesmo a outras áreas da engenharia. Ainda que o próprio termo Ciência possa ser questionado enquanto universal e atemporal, a sua ética e racionalidade são capazes de dar um norte a ações de natureza mais prática e de definição de políticas.

Num processo complexo como o de renovação de um método de projeto, surgem questões de ordem prática, mas também política, sendo desta última a natureza da decisão final sobre alterações formais. Tais decisões são eficazes quando apoiadas no melhor conhecimento disponível. 0 tipo de mudança em análise passa por uma base científica qualificada. Não por acaso países mais avançados cientificamente possuem, via de regra, normas mais avançadas (Soares et al., 2009). Ao longo de décadas, e até bem recentemente, o órgão federal responsável no Brasil por renovar normas viárias, o Departamento Nacional de Infraestrutura de Transportes (DNIT) não se alinhou, pelo menos em termos de conhecimentos estabelecidos, a órgãos de referência em outros países, a despeito de tentativas da Academia e de parte do seu próprio corpo técnico. Isso acarretou em significativo atraso dos estados da arte e da prática no país, agravado pelo fato de estados e municípios, em sua maioria, aguardarem um norteamento federal para suas atualizações de normas e métodos. Tal atraso no setor produziu um elevado preço que vem sendo pago pela sociedade brasileira.

\section{PROGRAMAS DE PESQUISA CIENTÍFICA}

Não é o objetivo discorrer em profundidade sobre diferentes propostas epistemológicas desenvolvidas por pensadores da Ciência, mas refletir sobre algumas destas para uma análise do caso específico do progresso da área de infraestrutura viária. O leitor é referido a Chalmers (2000) para uma reflexão sobre a Filosofia da Ciência, além de autores clássicos que constam nas referências (Khun, 1962; Popper, 1963; Feyerabend, 1977; Lakatos, 1979).

A pesquisa na área viária, assim como na maior parte das áreas de engenharia, possui um forte caráter empírico e indutivista. Num exemplo do Indutivismo, o fato de diversos cisnes brancos serem observados em lugares e tempos diferentes não permite afirmar que todos os cisnes são brancos, afinal, não importa quantos cisnes brancos sejam observados, se um único cisne de outra cor fosse observado, ficaria invalidada a afirmação de que há somente cisnes brancos. Este é o problema clássico da Indução, ou seja, o de se pretender que aspectos particulares levem a conclusões universais. Como alternativa ao Indutivismo, Popper (1963) introduziu o Falsificacionismo (ou Falibilismo). Enquanto no primeiro as observações servem para 
testar a validade de uma teoria, numa espécie de verificacionismo, na proposta popperiana, as observações servem para refutar as teorias. No falsificacionismo, admite-se que observações não antecedem uma dada teoria, mas a pressupõe, sendo derivadas dela e planejadas para testala. No caso da infraestrutura viária, a estrutura de conhecimento desenvolvida para compreensão de aspectos como, por exemplo, a fadiga de pavimentos, direcionará a forma da observação seletiva efetuada em campo, assim como ensaios laboratoriais, de maneira que pode-se estar preterindo teorias em função da teoria atualmente escolhida para testes, o que não contribui para o avanço mais célere do conhecimento. Não se deve perder de vista a existência desta estrutura anterior e definidora, por mais consistente que pareça, sob o risco de se ficar longamente refém da mesma. Daí a importância de Programas de Pesquisa que possam contestar a estrutura de conhecimento existente. Ao seguir-se um determinado Programa, é importante manter-se o espírito crítico falsificacionista, que exige que as hipóteses científicas sejam claras e falseáveis, e trabalhar obstinadamente para falseá-las. Entende-se que somente assim se produz Ciência. Quanto mais falseável for uma teoria, melhor, pois significa que ela é capaz de produzir um maior conteúdo informativo e que afirmações podem ser contestadas e, eventualmente, falseadas.

0 método nacional de dimensionamento de pavimentos antigo (Souza, 1981) partia de uma teoria pouco abrangente e pouco falseável, afinal sequer se arriscava em previsões sobre a evolução de trincas ou de afundamentos. Qualquer método que ouse realizar tais previsões está mais propenso a ser falseado, justamente por ampliar suas afirmações, ou seja, é mais abrangente. A lógica do método recentemente capitaneado pelo DNIT se arriscou na previsão do trincamento, porém ainda não da deformação permanente do sistema de camadas incluindo o revestimento. Uma coleta de dados de campo sistemática, mesmo à luz da concepção do próprio método, poderá validar ou não a proposição de previsão do trincamento. Seguindo-se a lógica popperiana, a proposição jamais poderá ser confirmada; no máximo almeja-se que seja suficientemente consistente para que não seja prontamente refutada. Pode-se questionar, como o fez Feyerabend (1977), que se uma experimentação (ou várias) não pode provar a validade de uma teoria, também não é suficiente para refutá-la. Daí o citado autor defender que uma metodologia de um Programa de Pesquisa não deve conter regras para os cientistas, mas apenas padrões. Numa área que ainda sequer percebeu a relevância do conhecimento para o seu avanço, ou pelo menos não o suficiente para montar uma política de investimento no conhecimento, são escassos os recursos para pesquisa e estes ficam restritos a linhas conservadoras, muitas vezes sob a égide da praticidade. Em tal ambiente, dificilmente se produz um conhecimento disruptivo, e falta celeridade para o avanço confiável do conhecimento. A potência financeira da área de infraestrutura viária no Brasil é tal que, ironicamente, ela seria justamente uma área fértil para pesquisas mais ousadas e descoladas do status quo.

Ainda sobre o Indutivismo, o mesmo está presente na lógica proposta para a atual pesquisa na pavimentação, na qual se medem em campo percentuais de área trincada de trechos para então confrontá-los com previsões apenas possíveis a partir de uma base de dados similar. $\mathrm{Ou}$ seja, uma base de dados (e.g., 40 trechos) serve para calibração de modelos, enquanto outra base similar (e.g., 20 trechos) serve para validação dos mesmos. A modelagem para a previsão é construída justamente para que haja harmonização com os dados existentes e não para que haja correspondência entre fenômenos físicos, considerando o corpo de conhecimento disponível. Aqui cabe a reflexão sobre o confronto entre Realismo e Instrumentalismo. Enquanto o primeiro busca descrever a natureza, o segundo busca instrumentos que relacionam um conjunto 
de estados observáveis com outros. Chalmers (2000) designa estes últimos de ficções convenientes. Na lógica instrumental, apreender a verdade não é o principal, mas sim a utilidade da elaboração conceitual como um instrumento. 0 referido autor destaca como a atitude realista deve ser preferida à instrumentalista, por possibilitar mais oportunidades de desenvolvimento. Esse não é o caso do Programa nacional hoje disponível para a infraestrutura viária, ainda que possa ser destacada a importância do Instrumentalismo enquanto escola pragmática do avanço do conhecimento na engenharia.

A nova lógica de predizer em campo a evolução do trincamento (ou deformação permanente) é bastante diferente da lógica do método de dimensionamento anterior, que não faz inferência sobre a evolução do dano. Na lógica empírica da década de 1960, não havia preocupação de que os ensaios laboratoriais fornecessem propriedades dos materiais. Também não foram considerados modelagem estrutural ou critérios de falha a partir dos conceitos da Mecânica. A ideia, também instrumental e de enorme simplicidade, era de se projetar um sistema de camadas de tal robustez, que os danos fossem evitados, sem pretensão de previsão de suas evoluções. 0 paradigma de então (Índice de Suporte Califórnia - CBR, estabilidade Marshall, entre outros), para usar a terminologia estabelecida por Khun (1962), foi revisto e vem sendo substituído no Brasil, ainda que lentamente, desde a década de 1980. A obtenção de propriedades dos materiais capazes de produzir previsão de comportamento em outras condições que não as experimentadas em laboratório ganhou relevância, à luz do que vinha ocorrendo desde a década de 1960 em outros países (SETRA/LCPC, 1978). A história demonstra que cientistas desenvolvem paradigmas com vistas a explicar aspectos relevantes da realidade. No ofício da Ciência, contudo, o cientista se depara com inconsistências no âmbito do paradigma no qual trabalha. Isso ocorreu no âmbito da pavimentação quando os ensaios empíricos e a metodologia a eles associada não mais deram conta de projetar adequadamente sistemas de camadas, que passaram a ser demandados por cargas maiores, em volume e magnitude, e a conter materiais (e.g., asfaltos modificados, misturas descontínuas, solos estabilizados quimicamente, etc) que sequer constavam na base de dados que ajudou a produzir o paradigma de então. Quando as inconsistências sobressaem, estabelece-se uma crise, detectada sobretudo no meio científico e em grupos da indústria próximos à fronteira do conhecimento. Segundo a estrutura de Khun (1962), a crise é resolvida quando surge um novo paradigma capaz de atrair um número crescente de cientistas e, subsequentemente, de profissionais.

Os novos paradigmas eventualmente encontrarão problemas de consistência, sendo então abandonados em prol do paradigma seguinte e, assim, sucessivamente. Estas descontinuidades são chamadas revoluções científicas, advindas do acúmulo de conhecimento. Os cientistas em uma determinada área são responsáveis por possibilitar que surja do interior da sua área uma forma de romper um paradigma propondo outro melhor. Acautelar-se com a construção do novo paradigma é, portanto, missão inescapável dos pensadores e tomadores de decisão da área viária de modo a evitar que uma vez mais se permaneça aprisionado por décadas em um paradigma que fique ultrapassado em pouco tempo. É por meio de uma ambiência garantidora do progresso da Ciência que um setor pode se manter imune a este estacionamento dispendioso à sociedade.

Neste breve passeio epistemológico sobre formas de progresso da Ciência, convém concluir com um autor que será útil para o propósito deste artigo. Para Lakatos (1979), não é por meio das hipóteses falseáveis de Popper, mas sim pela concorrência entre Programas de Pesquisa, mesmo quando conflitantes, que a Ciência se move. Entenda-se Programa de Pesquisa não como 
projetos de grupos individuais, mas sim um contexto amplo da pesquisa de uma área num dado momento. Nos termos do citado autor, trata-se de um macro Programa para as pesquisas futuras, sendo constituído fundamentalmente por: um Núcleo Central, representado por um conjunto de hipóteses consideradas irrefutáveis pelos que dominam o conhecimento da área; um Cinturão Protetor, passível de ser contestado e representado por um conjunto de hipóteses auxiliares ou métodos que, como o nome indica, protege o Núcleo Central; e heurísticas - positivas e negativas - que orientam os pesquisadores sobre o que pode ou não ser aceito no Programa. A heurística positiva lida com as diferenças entre experimentos e teoria, e tenta ajustar a própria teoria, sem refutá-la. Neste caso, não se abandona facilmente uma teoria por haver sido falseada. Há tenacidade. A heurística negativa mostra aquilo que não se pode contestar no Programa, ou seja, as ideias irrefutáveis que compõem o Núcleo Central.

Transpondo a epistemologia de Lakatos para o corpo de conhecimento da infraestrutura viária, o Núcleo Central do Programa de Pesquisa que se estabeleceu desde a década de 1960 no Brasil envolvia a confiança (i) no CBR dos solos como indicador da capacidade de suporte das subcamadas, (ii) no número de operações de um eixo padrão, N, como indicador do tráfego, e (iii) numa combinação entre as espessuras das camadas e os dois indicadores anteriores de modo a produzir uma estrutura que não comprometesse a plataforma de sustentação (subleito). CBR e N são ainda hoje protegidos por um Cinturão enraizado no conservador estado da prática no Brasil. Todavia, o país vive um momento de transição para um novo Programa de Pesquisa. Manteve-se no novo Núcleo o indicador do tráfego, $\mathrm{N}$, ainda que com suas limitações. Aboliu-se o CBR e incorporaram-se dados de campo levantados no âmbito da Rede Tecnologia da Petrobras, que passam a ser incontestáveis, como se fora um Núcleo Central. Trata-se de um patrimônio de informação fruto do esforço de muitos grupos e que custou milhões de reais. Sublinha-se a relevância desse patrimônio que, aliado ao esforço de explicar os dados observados (adotados como verdade), constitui a revolução de conhecimento que a área está vivendo (adoção de cálculo estrutural elástico e de ensaios cíclicos para caracterização de materiais) e permitirá provavelmente a próxima rodada de aperfeiçoamento, com modelos de dano contínuo e sofisticação do cálculo estrutural. Porém, o país encontra-se sem outra alternativa, o que representa um risco. Qualquer pesquisa sobre dimensionamento hoje no Brasil, até por não se dispor de outra base de dados, não pode desconsiderar a atual, ainda que sejam encontradas anomalias, fatos problemáticos, inconsistências, etc. Entre os elementos do Cinturão Protetor do Programa de Pesquisa associado ao novo método objetivado pelo DNIT estão ensaios laboratoriais que, sabidamente, contêm falhas conceituais, como é o caso do ensaio de carregamento cíclico até a ruptura adotado para o dimensionamento quanto à fadiga. Ainda que possa ser percebido como um progresso, não se deve perder de vista que o ensaio sequer garante o acesso a uma propriedade de fadiga, produzindo ruptura por excesso de acúmulo de deformação de fluência (Babadopulos et al., 2015).

Conforme mencionado, na heurística negativa, que estabelece as ideias consideradas irrefutáveis, é proibido que o Núcleo seja declarado falso por causa de anomalias observadas. No caso corrente da área viária, o método eventualmente proposto não será refutado caso os modelos de evolução não funcionem em projetos futuros. Será mais provável que se considere que os ensaios laboratoriais estejam equivocados. 0 Cinturão Protetor tenderá então a ser ajustado, afinal, sempre é possível explicar anomalias por meio de modificações ad-hoc, como alterações em coeficientes de funções de transferência ou no formato dessas curvas. Isso poderá se dar por 
meio da heurística positiva num conjunto de sugestões sobre como modificar o Cinturão Protetor, permitindo que o Programa progrida de forma incremental.

Lakatos (1979) discorre de que forma um Programa, que parte comumente com anomalias, pode progredir por meio de modelos de crescente complexidade. O Programa é considerado progressivo se é capaz de prever fatos novos devidamente comprovados, e é considerado regressivo em caso contrário, pela não comprovação ou pela não previsão de fatos novos. Ao incluir, por exemplo, modelos de clima (efeito da umidade dos solos ou da temperatura no revestimento) num método de dimensionamento dentro da lógica atual se estaria progredindo no Programa, que seria progressivo caso este aumento de complexidade viesse a ser corroborado pelas observações de evolução de dano em climas distintos.

\section{BREVE HISTÓRICO NACIONAL}

Embora tenha-se fornecido breves relatos dos Programas de Pesquisa Científica da área viária no Brasil, sendo um antigo e um outro em processo de implantação, nesta seção se faz um histórico de desenvolvimento do rodoviarismo no país, tentando associá-lo ao desenvolvimento da Ciência na área. $\mathrm{O}$ avanço da Ciência em boa parte dos campos de conhecimento, incluindo as Engenharias, passa pelo (i) desenvolvimento de pesquisas científicas (projetos e Programas), (ii) formação e atração de recursos humanos, (iii) suporte à infraestrutura física e, por fim, (iv) divulgação para a avaliação dos pares, de modo que qualquer avanço seja criticado para a indispensável retroalimentação. Quando um destes pilares falha, corre-se o risco de se produzir má ciência, ou mais claramente, não se produzir ciência ou progresso de conhecimento científico ou de Engenharia.

No Brasil, viveu-se um momento rico no avanço de conhecimento rodoviário a partir da segunda metade da década de 1960, trazendo-se uma compreensão aprimorada e novas técnicas fruto da cooperação com centros internacionais. Ensaios de carga repetida foram introduzidos no país nos anos 1970 e as primeiras teses de doutorado na área surgiram na década de 1980, sendo crescentes nos princípios de 1990. É nesta década que se registram as primeiras rodovias concessionadas e a introdução dos asfaltos modificados, sendo que ambos tiveram um impacto no tipo de pesquisa à época, ou seja, no Programa de Pesquisa Científica. 0 período de cerca de 30 anos entre a segunda metade da década de 1960 até os fins de 1990, num resumo simplificado, fecha um primeiro bloco de progresso de conhecimento do setor viário brasileiro. Consolidava-se a pesquisa, ainda que concentrada em poucos centros e envolvendo prioritariamente a caracterização empírica de materiais. Novos desafios passaram a exigir mais do Programa de Pesquisa então estabelecido que, vale ressaltar, contribuiu para a construção de uma parcela significativa do patrimônio viário nacional.

Surge então um segundo período no fim da década de 1990 e início dos anos 2000. Além de novas necessidades de conhecimento, tanto para academia como para indústria, este período coincidiu com a Lei dos Royalties do Petróleo. Esta lei possibilitou que a Petrobras, por meio do seu Centro de Pesquisa (Cenpes), coordenasse projetos em cooperação com universidades, fazendo uso de recursos até então não vistos no cenário nacional para pesquisa em pavimentação. Há então um avanço substancial na infraestrutura física de um número maior de laboratórios e, consequentemente, observa-se um aumento na formação de recursos humanos, uma sofisticação nas teses e dissertações, que passaram a ter um alinhamento crescente com os principais centros internacionais. Estes itens caminharam juntos da melhoria da pós-graduação stricto sensu. Os 20 anos subsequentes colocaram o Brasil no mapa da pesquisa internacional, embora 
mais como seguidor do que como definidor da agenda. 0 período é marcado pela tentativa de se estabelecer de forma definitiva um segundo Programa de Pesquisa Científica, trazendo a Mecânica dos Pavimentos para o centro das discussões não apenas acadêmicas, mas também da indústria. Ainda que o Núcleo Central de um novo Programa já se encontre hoje relativamente bem estabelecido em boa parte da academia nacional e até da indústria, sobretudo concessionárias, ainda não há propriamente um consenso sobre alguns aspectos que formam o entorno deste Núcleo, ou seja, o seu Cinturão Protetor como, por exemplo, a melhor forma de se caracterizar a rigidez e a fadiga de misturas asfálticas ou o efeito do clima na resposta estrutural.

A situação atual é de uma comunidade científica nacional inserida internacionalmente, com vários de seus integrantes, inclusive jovens doutores, com elevado grau de reconhecimento. A realização de eventos de portes diversos e em diferentes regiões do país, contando com proeminentes pesquisadores nacionais e internacionais, produz sinais de indicadores científicos alinhados com o que há de melhor no mundo. Isso demonstra como é fértil este campo do conhecimento no nosso país, apesar de que a necessária irrigação não foi sistemática e coordenada, além de haver sido deveras dependente dos recursos dos royalties do petróleo.

Ainda que o foco seja na Ciência, abre-se um comentário para a relação do conhecimento com a indústria, hoje abrigado no termo Inovação. Embora envolva recursos consideráveis, a área rodoviária no país não se destaca como inovadora. No âmbito das empresas pequenas, médias ou grandes, há pouco incentivo para inovações, sendo restrito o que é feito em termos de PD\&I (Pesquisa, Desenvolvimento \& Inovação), à exceção dos recursos investidos pela Petrobras/ANP e os Recursos de Desenvolvimento Tecnológico (RDT) da Agência Nacional de Transporte Terrestre (ANTT) para pesquisas ligadas a concessionárias. Este não é o caso em outros países, onde o investimento em PD\&I é determinante para a competitividade das empresas. Os Centros de Pesquisa das grandes empreiteiras europeias são frequentemente melhor equipados do que os melhores Centros de Pesquisa brasileiros. 0 reduzido recurso de pesquisa é incompatível com o alto volume de recursos da área viária no país. Pode-se inclusive considerar que Departamentos Estaduais de Rodovias, Prefeituras e o DNIT simplesmente têm optado por não investir em avanço de conhecimento, afinal é irrelevante o percentual dos respectivos orçamentos investido em PD\&I dentro das melhores práticas do fomento científico e tecnológico. Tratase de um aspecto que precisa urgentemente de articulação entre gestores públicos, das empresas e da academia, tendo o potencial de revolucionar o segmento viário. Isso teria reflexos na qualidade para o usuário, na economia (de recursos financeiros e tempos de viagem), no meio ambiente (melhor aproveitamento dos recursos naturais e de resíduos) e na saúde dos trabalhadores (menos voláteis emitidos, por exemplo).

Parte-se a seguir para um contexto mais técnico, refletindo-se sobre os conhecimentos necessários às pesquisas em infraestrutura viária para, em seguida, serem apontadas oportunidades de progresso. À luz das necessidades técnicas, delineiam-se aspectos essenciais de um Programa de Pesquisa Científica que forneça a devida confiança em um futuro de maior conhecimento para o setor.

\section{ALGUNS ASPECTOS TÉCNICOS}

Para qualquer projeto de engenharia envolvendo análise estrutural e modelos de base física , ou seja, da alçada da Mecânica, precisa-se conhecer três aspectos: (i) Materiais, (ii) Contorno (particularmente o carregamento), e (iii) Geometria. Determinadas estruturas, como aeronaves, têm no terceiro item uma complexidade que pode ser mitigada pelo uso de programas gráficos, 
enquanto outras, como a de pavimentos, têm seu principal desafio nas relações constitutivas dos materiais, que podem incorporar o efeito do tempo e do clima, e nas cargas, sem desafios particulares quanto a geometria. Esta seção tratará, portanto, das dificuldades atreladas a materiais, ao contorno, e às falhas observadas nas estruturas de pavimentos.

\subsection{Materiais}

Na superestrutura de pavimentos (acima do subleito), há complexidade tanto no revestimento quanto nas subcamadas. Quando o revestimento é asfáltico, surgem questões ligadas ao comportamento termo-viscoelástico do ligante asfáltico, que o tornam dependente da temperatura e da frequência de carga. Tal comportamento é passado às escalas superiores, do mástique à mistura asfáltica. A adesividade ligante-agregado, propriedade de interface entre estes constituintes (que pode ser vista como um terceiro constituinte), é relevante, devendo ser considerada à luz de propriedades físico-químicas. Outros revestimentos, como o concreto de cimento Portland, possuem desafios semelhantes de compreensão dos constituintes e interação entre estes. Ainda que este documento trate dos pavimentos asfálticos, as reflexões cabem para outros revestimentos. 0 Brasil encontra-se alinhado com o que há de mais atual em termos de conhecimento científico, mas em termos de aplicação, permanece aquém do estado da prática em outros países. Qualquer generalização requer cautela e, claramente, há exceções de obras viárias com qualidade próxima a de países avançados. Mas o panorama geral do país cabe nas presentes considerações. Parte da reflexão consiste em questionar o porquê de não ser amplamente difundido o uso de ensaios reológicos dos ligantes, incluindo fadiga e deformação permanente. Por que, no Brasil, mesmo em obras relevantes como pistas de aeroportos, não há uma maior preocupação com um valor mínimo de compliância não recuperada do ligante aplicado (Vnr), com a forma ou a granulometria dos agregados a fim de se estabelecer o melhor intertravamento, para além de faixas granulométricas normatizadas? Do lado da execução, quais obras possuem controle da umidade dos agregados, ou controle da deflectometria, camada a camada, de modo a garantir baixa deformabilidade da estrutura?

No que toca às subcamadas, há enfim um avanço do estado da prática, que é a substituição do CBR pelo módulo de resiliência (MR) como parâmetro da capacidade de suporte. Diversos trabalhos apontam a relevância do uso da resposta estrutural em modelos empíricos que fornecem a evolução de defeitos. Embora o DNIT tenha normatizado o ensaio de MR desde a década de 1990, ainda é significativo o número de obras viárias no país que não fazem uso deste parâmetro e, por conseguinte, da análise estrutural. 0 método recém desenvolvido com o apoio do DNIT traz um avanço e ensaia inaugurar um novo Programa de Pesquisa. Todavia, o Programa proposto possui fragilidades de partida, sobretudo nos ensaios de caracterização dos materiais dos revestimentos. Como mencionado, há conhecimentos mais avançados e estabelecidos na própria comunidade nacional. Considerando estes ensaios como parte do Cinturão Protetor, é possível que o Programa progrida por meio do ajuste deste Cinturão. Porém, perdeu-se uma oportunidade de colocar ensaios mais fundamentais no Núcleo Central, e não como aspectos auxiliares passíveis de serem melhorados no curtíssimo prazo. Cedeu-se à visão instrumentalista, optando-se por ensaios mais simples e conhecidos no país. No instrumentalismo, a atitude para com a Mecânica tende a ser conservadora e a inibir o progresso. No caso, ensaios mais rigorosos trariam maior grau de fertilidade ao Programa, o que permitiria ramificações das linhas de pesquisa em caracterização de materiais. 
Como uma palavra final sobre o tema Materiais, ainda há bastante margem para se incorporar na pavimentação conhecimentos consagrados em áreas mais mecanicistas como geotecnia ou estruturas, e.g., modelos plásticos, efeito da sucção na rigidez, efeito da interface entre camadas. É visível a falta de uma melhor base mecanicista no país no segmento viário, algo que deveria ser mitigado com a interdisciplinaridade envolvendo outras áreas no Programa de Pesquisa, que deve ser bem estruturado e com elevada capacidade de produzir novas linhas de pesquisa para pesquisadores com habilidades e interesses diversos.

\subsection{Contorno: o Tráfego}

Se há dificuldades associadas ao item anterior para o progresso da área viária, no que toca ao tráfego a situação é ainda mais atrasada. A análise estrutural dos pavimentos é, via de regra, realizada considerando-se cargas estáticas, portanto, distante da situação real. Trata-se de uma simplificação cujo verdadeiro impacto poucos pesquisadores se dedicam a investigar.

O setor rodoviário nacional segue refém do número $\mathrm{N}$ como parâmetro de tráfego no projeto de pavimentos. Tal simplificação pode ser atenuada por considerações como, por exemplo, a de que a carga das rodas dos eixos possui uma variação lateral de cerca de 1,0 m e, portanto, o número de passagens de um determinado tipo de eixo sobre um ponto específico do pavimento é na verdade inferior ao número de passagens deste tipo de eixo na seção transversal da rodovia, uma vez que alguns eixos passarão a centímetros de distância do ponto em análise. Esta consideração do lateral wander pode multiplicar o $\mathrm{N}$ permitido ou, caso não seja considerado, projeta-se a favor da segurança. $O$ fato é que, idealmente, todos os eixos previstos poderiam ser considerados, desde que se dispusesse de uma ferramenta de análise capaz de fazer senso das diversas passagens. Isso será possível com modelos constitutivos que possibilitem a degradação dos materiais nas diferentes camadas à medida que os eixos solicitem a estrutura. Para que o conhecimento avance nesta direção, que é a representação adequada da realidade, o país precisa de um Programa de Pesquisa Científica melhor qualificado em análise estrutural de sistemas de camadas. Entretanto, historicamente, o Brasil tem formado poucos mecanicistas, algo que dificulta colocar as ferramentas disponíveis em um patamar mais sofisticado e sem dependências de programas importados, o que representa um risco. Alguns apontarão que não se trata de uma prioridade, pois o estado da prática do país sequer absorveu ainda a análise simplificada. Tal argumentação acaba contribuindo para um atraso científico sob a justificativa de que o mesmo deve estar harmonizado com o atraso da prática. A presente reflexão contesta esta argumentação e instiga um Programa que valorize o conhecimento mais aprofundado, capaz de colocar o Brasil numa liderança no desenvolvimento do conhecimento e na produção de ferramentas que possam ser usadas internacionalmente.

\subsection{Falhas}

Os pavimentos asfálticos podem apresentar diferentes tipos de defeito, sendo considerados mais impactantes nas vias brasileiras a deformação permanente e o trincamento por fadiga. A investigação sobre estes defeitos se relaciona com as premissas estabelecidas no Programa de Pesquisa Científica. Alguns aspectos são brevemente comentados a seguir no que toca aos revestimentos asfálticos.

\section{Deformação Permanente}

A prevenção para a formação do Afundamento de Trilha de Roda deve se iniciar com a escolha do ligante. Em laboratório, além das caracterizações que se referem ao ensaio de penetração, 
ponto de amolecimento, determinação das temperaturas de usinagem e compactação e Performance Grade, pesquisadores utilizam o ensaio de fluência e recuperação sob tensão múltipla, o MSCR (Multiple Stress Creep Recovery), já normatizado nos EUA. Mesmo identificando boas correlações do MSCR com a deformação permanente em campo, é necessário atentar para situações em que a limitação de recursos impede a escolha do ligante ideal, especialmente se ainda há alternativas de fontes de agregado e curvas granulométricas. Há metodologias que visam a otimização da escolha das proporções dos agregados, sendo as mais disseminadas o Método Bailey e a Faixa de Agregados Dominantes, e técnicas de caracterização com Processamento Digital de Imagens para auxílio na escolha de agregados com angularidade, textura e forma adequadas. Existem ainda ensaios que buscam hierarquizar e/ou extrair propriedades mecânicas de misturas asfálticas. 0 ensaio uniaxial de carga repetida provê dados para a curva 'deformação permanente medida vs. número de ciclos' e o denominado FN (Flow Number) indica a ruptura do corpo de prova (CP). Quanto maior o FN, mais resistência possui a mistura, porém, essa informação não é suficiente para prever a evolução da deformação permanente. Ensaios de carga repetida com confinamento triaxial permitem a obtenção de propriedades de materiais para a previsão de comportamento, além de uma melhor reprodução da situação de campo (Bastos et al., 2016). No Brasil, além de pesquisas que visam a investigação e a adequação de ensaios triaxiais, deve-se ter uma constante preocupação com a organização do banco de dados e o acompanhamento da evolução da deformação permanente em trechos experimentais, a fim de validar sistematicamente os parâmetros tanto para FN quanto para os resultados e protocolos do ensaio triaxial de carga repetida, com vistas ao progresso do método de dimensionamento de pavimentos.

\section{Fadiga}

Ensaios cíclicos em CPs de diferentes geometrias são frequentemente usados para analisar o dano por fadiga. Um estado homogêneo de tensões nos CPs em laboratório (e.g. em ensaios tração-compressão) é necessário para que não se dependa de hipóteses adicionais durante a interpretação dos resultados. Este aspecto ainda não foi bem assimilado pela academia nacional e segue incompreendido na área. Sem esta exigência, não se pode traduzir adequadamente um resultado laboratorial fornecendo uma propriedade do material para uma estrutura real a partir de modelagem, uma vez que nem no caso do ensaio controlado em laboratório se obtém uma propriedade de maneira confiável. Ao se realizar um ensaio num estado homogêneo, tem-se uma propriedade para uma situação de solicitação específica (e.g. tração-compressão), que pode ser considerada sempre que esta solicitação surja na configuração de campo, ainda que proveniente de um carregamento em flexão, por exemplo. Qualquer outra tentativa de comunicar o ensaio de fadiga em laboratório com o campo terá uma forte e desnecessária dose de empirismo. A comunidade tem buscado formas de acessar em laboratório a resistência à fadiga dos materiais. No Brasil, é comum o uso do ensaio de força controlada por tração indireta (nãohomogêneo), apesar das limitações descritas em Babadopulos et al. (2015).

Para a previsão de desempenho em campo, a fadiga nos pavimentos também pode ser considerada de diversas formas. Uma delas é limitando-se a tensão ou a deformação de tração no revestimento a valores documentados como razoáveis. Ou seja, projeta-se o sistema de camadas objetivando-se limitar estas respostas. Trata-se de uma abordagem simples e capaz de produzir resultados práticos, muito embora não forneça qualquer indicativo de evolução do trincamento no tempo. Limita-se a prevenir este defeito, num exemplo de instrumentalismo. Outra forma, é buscando uma expressão para evolução do trincamento relacionando resultados de ensaios 
laboratoriais de fadiga utilizados para previsão de comportamento em campo com dados de campo de trechos experimentais, e.g. o percentual de área trincada (\%AT), que corresponde a quantidade relativa de células pré-definidas trincadas no total de células avaliadas. Os valores obtidos em campo podem ser plotados em um gráfico ‘\%AT vs. dano’ (previsto por meio de modelos que envolvem dados de laboratório) correspondente a data de medição em campo. A comparação dos resultados de previsão de desempenho com o constatado em campo e a consequente utilização de funções matemáticas de ajuste entre essas duas constatações (cálculo vs. observação) para um conjunto de dados previamente obtido produz as "Funções de Transferência" (FT). Estas permitirão, para observações futuras, tentar prever o desempenho a partir de um cálculo que considere as condições em campo, a geometria das camadas e as propriedades dos materiais. Há exemplos nacionais de abordagens desse tipo, utilizando diferentes conjuntos de hipóteses simplificadoras, de ensaios, de critérios e de operações de modelagem (Nascimento, 2015; Fritzen, 2016; Santiago et al., 2019), ao que se refere neste trabalho como "sistemas de dimensionamento", cada um com diferentes FTs. Esses sistemas podem ser codificados em programas computacionais, como é o caso do LVECD, do SisPav, do MeDiNa e do CAP3D-D. Observe-se que a seleção do sistema impõe a escolha das FTs e dos parâmetros de materiais a serem utilizados, que não podem ser adotados de acordo com a preferência do usuário.

\section{O FUTURO DOS PROGRAMAS DE PESQUISA CIENTÍFICA PARA A INFRAESTRUTURA VIÁRIA NACIONAL}

O conhecimento da área de infraestrutura viária avançou. No dimensionamento dos pavimentos, a discussão não é mais propriamente entre métodos empíricos ou mecanístico-empíricos. Numa comparação, o segundo não apenas nega, mas sequer permite afirmações que envolvam elementos do primeiro. Por exemplo, não se pode afirmar algo com confiança em termos da resposta estrutural do revestimento (maiores ou menos deformações) em virtude de um aumento do CBR das subcamadas. As filosofias de embasamento das duas abordagens são significativamente distintas, o que não permite que sejam comparadas por meio da mesma lógica. Podem ser comparadas confrontando-se cada uma com observações sobre o desempenho estrutural no campo e verificando-se qual é a mais compatível à luz de seus respectivos termos. A experiência desempata hipóteses. 0 fato é que o método empírico há tempos, ou desde sempre numa análise mais exigente, é incapaz de ser confrontado com observações como a evolução de danos nos pavimentos.

Se o método de dimensionamento empírico do DNIT não dialoga com metodologias mais modernas, uma situação distinta surge quando se consideram métodos que podem compartilhar uma base conceitual equivalente, sendo que um, por exemplo, considera a sucção dos solos na rigidez das subcamadas ou a velocidade dos veículos e seus respectivos impactos na resposta estrutural. No processo de escolha entre métodos, assim como quando se deve escolher entre teorias, deve-se questionar: quais critérios devem ser preferidos? Simplicidade ou maior oportunidade de desenvolvimento? É, por acaso, a escolha de ordem subjetiva? Se sim, a proximidade entre envolvidos no desenvolvimento e a propaganda passam a ser relevantes? Por que um cientista escolherá trabalhar em aspectos de um método específico ou numa teoria e não em outra? No caso da pavimentação nacional, o que fará com que grupos abandonem pesquisas que comparem, por exemplo, os CBRs de diferentes solos, ou a vida de fadiga por compressão diametral de diferentes misturas? As respostas estarão associadas à disponibilidade de 
recursos e à estratégia de um Programa de Pesquisa Científica para a área de infraestrutura viária no Brasil. Tal Programa pode inclusive contemplar caminhos simultâneos com diferentes níveis de conhecimento, balanceando complexidade e utilidade.

Diante do exposto, há um papel relevante que é o de orquestrar a disputa entre métodos e teorias na área de infraestrutura viária, visando ao estabelecimento do mais eficaz Programa de Pesquisa. Os pesquisadores devem estar minimamente confortáveis para enveredar por caminhos alinhados com o que houver de melhor na Ciência, sabendo que contarão com alguma forma de apoio. Sem um conforto mínimo, dificulta-se o pensamento inovador na pesquisa e joga-se o jogo seguro do financiamento. Grupos de pesquisa estarão frequentemente limitados por recursos físicos (laboratório e equipamentos) e humanos (quantidade e qualidade), mas não deveriam jamais ficar limitados por um contexto que iniba a criatividade e a liberdade de investigação.

Um Programa de Pesquisa Científica de sucesso no país foi a Rede de Tecnologia em Asfaltos da Petrobras cujos resultados são indiscutíveis em termos de melhoria da infraestrutura para pesquisa, formação de pessoal e resultados práticos para a própria empresa patrocinadora e para todo o segmento rodoviário. Tratou-se de uma forma de fomento que foi capaz de elevar o setor da infraestrutura viária a outro patamar em termos de Ciência, nas universidades e no próprio Cenpes. A citada Rede ofereceu oportunidades objetivas e acomodou um grande número de grupos. No início de um Programa não se pode garantir sucesso, pois não se pode antever se as oportunidades serão devidamente aproveitadas e produzirão frutos. A Rede é uma boa referência para programas adicionais que são absolutamente necessários no país, até pela necessidade do envolvimento de mais pesquisadores, em frentes mais diversificadas, tanto em profundidade como em amplitude de atuação científica.

Uma aspecto relevante é avaliar como aprimorar o Programa hoje estabelecido e ainda propor alternativas, não apenas à Petrobras, mas a outros agentes de fomento. A Tabela 1 apresenta, de forma simplificada, uma ideia dos Programas de Pesquisa das últimas décadas na área de pavimentos. Percebe-se que no método antigo são inegociáveis o CBR e o N, sendo que ajustes podiam e foram feitos ao longo dos anos nos coeficientes estruturais das camadas ou na consideração de um fator climático. Com o surgimento dos ensaios de carga repetida e da análise estrutural, foram definidos critérios de tensões (ou deformações) no fundo do revestimento e no topo do subleito, que passaram a ser o Núcleo deste novo tipo de método. Valores aceitáveis foram ajustados de acordo com a situação, e outras sofisticações foram consideradas como, por exemplo, níveis distintos de aderência na interface revestimento-base.

Mais recentemente, principalmente após o MEPDG (Mechanistic Empirical Pavement Design Guide) norte-americano, passou-se a uma nova lógica nos métodos mecanístico-empíricos. Outras formas de análise estrutural, como a viscoelástica linear, foram consideradas, e aprofundou-se a discussão sobre os ensaios adequados para a caracterização dos materiais, sobretudo das misturas asfálticas. Tais discussões prosseguem, até pelo nível de complexidade dos fenômenos que surgem nos ensaios mecânicos e, aparentemente, estes serão ajustados à medida que mais dados forem coletados para validação dos métodos desenvolvidos.

Independentemente do nítido progresso, cabe a reflexão sobre quais elementos do Núcleo Central que se desenha hoje podem aprisionar o Programa de Pesquisa. Tal reflexão é importante pois, como já mencionado, é essencial que um Programa traga em si a potencialidade para se atualizar e se autocorrigir, ou seja, traga em si uma fertilidade. No caso do Brasil, a base de dados usada para o desenvolvimento de FTs nos trabalhos realizados na nova lógica passou a 
ser inegociável e inatacável, até porque sem a mesma, não haveria quaisquer das proposições. Pode-se argumentar que esta base irá crescer progressivamente e muito esforço segue sendo colocado neste sentido. Contudo, a coleta de dados, principalmente no que toca aos dados de campo, possui um tempo particular, que leva mais de 10 anos, pela própria necessidade de levantamentos da evolução de danos ao longo da vida útil dos segmentos experimentais que calibrarão o método. Alternativas de aceleração de dano incluem Simuladores de Grande Porte. Todavia, um risco evidente é que os dados serão coletados sob a óptica da lógica estabelecida, inclusive com as próprias ferramentas de coleta contendo limitações. Outro risco é a fragilidade dos dados de tráfego, sendo que as cargas reais, na grande maioria, não são contadas e pesadas. São consideradas cargas de projeto, uma limitação séria em uma parte absolutamente central do método.

Tabela 1 - Resumo de Programas de Pesquisa da infraestrutura viária nacional

\begin{tabular}{|c|c|c|}
\hline Programa de Pesquisa & Núcleo Central & Cinturão Protetor \\
\hline Empírico (DNIT, 1966, 1981) & $\begin{array}{l}\text { CBR das camadas, } \\
N \text { para tráfego }\end{array}$ & $\begin{array}{l}\text { Coeficientes estruturais, efeito da } \\
\text { drenagem, fator climático }\end{array}$ \\
\hline $\begin{array}{l}\text { Mecanístico-empírico - Versão } 1 \text { (Motta, } \\
\text { 1991) }\end{array}$ & $\begin{array}{l}\text { Análise elástica linear, } \\
\text { MR para as camadas, } \\
\text { N para tráfego, critérios de falha empíri- } \\
\text { cos (fadiga e deformação permanente) }\end{array}$ & $\begin{array}{l}\text { Possibilidade de variação da interface } \\
\text { entre camadas, ajuste dos valores dos } \\
\text { critérios de falha estabelecidos }\end{array}$ \\
\hline $\begin{array}{l}\text { Mecanístico-empírico - Versão } 2 \text { (Nasci- } \\
\text { mento, 2015; Fritzen, 2016; Santiago et al., } \\
\text { 2019) }\end{array}$ & $\begin{array}{l}\text { Banco de dados organizado, análise elás- } \\
\text { tica ou viscoelástica linear, MR para sub- } \\
\text { camadas, } \mathrm{N} \text { ou espectro de cargas para o } \\
\text { tráfego }\end{array}$ & $\begin{array}{l}\text { Lateral Wander dos eixos para trá- } \\
\text { fego, ensaios de fadiga e deformação } \\
\text { permanente para misturas asfálticas }\end{array}$ \\
\hline
\end{tabular}

Quais as boas práticas então para que o Brasil garanta uma resiliência mínima para um novo Programa de Pesquisa Científica? Assim como assumiu enfim o seu papel de repensar o método, ainda que com as já citadas limitações, o DNIT deveria urgentemente traçar um plano de coleta progressiva de dados em novas pistas experimentais, cobrindo amplas áreas regionais, até para considerar o impacto do clima num país continental. Estas pistas deveriam ter seus tráfegos contados e pesados, de modo a eliminar este elo fraco da metodologia atual. Outro ponto essencial é a frequência da carga, traduzida pela velocidade dos veículos carregados, algo também possível em um acompanhamento mais refinado do tráfego. Trata-se de um esforço urgente e essencial que, caso não seja feito por se confiar nas poucas pistas adicionais que serão incorporadas no Programa da Petrobras, tornará todo o sistema de pesquisa refém de uma base de dados com as limitações já colocadas. É passada a hora de os órgãos rodoviários brasileiros, em nível federal e estadual, perceberem que não farão avanços sem investimento num Programa de Pesquisa Científica. E isso requer apenas um investimento em P\&D do equivalente a cerca de 1 $\mathrm{km}$ de rodovia construída, ou seja, algo como R\$ 1 milhão a R 2 milhões por ano em cada um dos laboratórios dos grupos de pesquisa espalhados pelo país. Tal investimento tem o potencial de transformar a área de infraestrutura no Brasil, tanto em termos de compreensão de fenômenos como da capacidade de previsão de desempenho das rodovias. É algo insignificante para o que se gasta no país com vias de má qualidade e incompreensível quando se consideram as melhores práticas de fomento internacional.

Concretamente, chamadas públicas por parte dos órgãos rodoviários como o DNIT e os DERs, envolvendo inclusive a iniciativa privada, deveriam ser planejadas, a exemplo de experiências internacionais. Com o devido financiamento e demandas claramente estabelecidas, desdobrase um Programa de Pesquisa Científica com impacto em todo o setor. Os grupos de pesquisa nas 
universidades do Brasil, de um modo geral, possuem um caráter acadêmico, ainda com pouca experiência no desenvolvimento de produtos e processos que possam ser colocados em planos de negócios capazes de alavancar empresas no segmento. As citadas chamadas públicas podem ser desenhadas visando contribuir para tirar o segmento de infraestrutura viária do atraso na formação de spin-offs (pequenas empresas criadas na universidade ou no seio de empresas existentes a partir de inovações que vão ao mercado). Eis um importante nicho de oportunidade para as políticas públicas de inovação na área viária.

\section{CONSIDERAÇÕES FINAIS}

É usual que o avanço do conhecimento dependa da existência de Programas de Pesquisa concorrentes, sendo que um macro Programa deixa de existir quando surge uma alternativa melhor. A própria lentidão do progresso observado na infraestrutura viária do Brasil desde a década de 1960 aponta para a urgência de um novo Programa que, inclusive, já se encontra aproximadamente traçado. 0 seu Núcleo Central deve possuir elementos da Mecânica dos Pavimentos e de uma base de dados robusta associada a informações de laboratório, mas, sobretudo, de levantamentos de campo, envolvendo tanto a caracterização dos materiais utilizados, como do tráfego e da evolução dos defeitos. Há de se avaliar as limitações dos dados hoje disponíveis de modo que se empreendam esforços para se dispor de uma base de dados cada vez mais confiável, até porque esta base possivelmente seguirá compondo o Núcleo Central do Programa.

À medida que novos projetos viários sejam feitos e os resultados em campo sejam comparados com as previsões, deve ser executada uma análise em retrospecto para alimentar o Programa de Pesquisa. Eventuais observações em conflito não necessariamente eliminarão o Programa. Ajustes no seu Cinturão Protetor entrarão em cena de modo que as predições sejam mais compatíveis com as observações. Decisões sobre priorizações do Relativismo ou do Instrumentalismo retornarão e espera-se que sejam feitas com mais Ciência e mais debate. Num futuro breve o novo Programa estará devidamente estruturado. Afinal, não se esperava que a superação do Programa anterior fosse instantânea. No processo que ainda resta, há de se buscar um pluralismo teórico, afinal, apenas visões distintas e muita discussão, numa ambiência apropriada, farão um Programa de Pesquisa Científica à altura da grandeza do Brasil. Espera-se que o mesmo tenha elevado grau de fertilidade e possibilite o desenvolvimento de muitas linhas de pesquisa, inclusive daquelas que eventualmente irão contestar o próprio Programa.

0 presente texto teve a ambição de fomentar a discussão sobre o futuro da pesquisa em infraestrutura viária no Brasil e também apontar caminhos para um método sistemático de revisão do conhecimento. A Ciência foi tomada como um modelo de inspiração. Veículos de divulgação científica possuem um papel chave e devem ser conhecidos e lidos pelos técnicos que assessoram os formuladores das políticas públicas do setor. Há muitos recursos em jogo. Não se justifica o país não ter um Programa de Pesquisa Científica bem estruturado e alinhado com o que há de melhor do conhecimento. Para além dos resultados em termos de melhor compreensão dos fenômenos, possibilidade de maior inserção e até liderança internacional e de aplicações práticas para a indústria, a sensibilização quanto ao financiamento também é crucial para atrair pesquisadores para a lida da Ciência na infraestrutura viária. Já há muitos jovens no país com boa formação neste campo de conhecimento e afins. Eles não podem ser desperdiçados. A eles pertence o próximo salto e aos mais experientes cabe pavimentar a Ciência das próximas décadas. Nas palavras de Abraham Flexner (1939) “0 verdadeiro inimigo da raça humana não é o pensamento destemido e irresponsável, esteja ele certo ou errado. 
O verdadeiro inimigo é aquele que molda o espírito humano de modo que ele não ouse abrir suas asas".

\section{AGRADECIMENTOS}

Ao CNPq pela bolsa de produtividade e, sobretudo, ao grupo de pesquisa do LMP/UFC, por me dar profundo propósito e uma ambiência de entusiasmo e aprendizagem.

\section{REFERÊNCIAS}

Babadopulos, L.F.A.L.; Soares, J.B.; Castelo Branco, V.T.F. (2015) Interpreting fatigue tests in hot mix asphalt (HMA) using concepts from viscoelasticity and damage mechanics. Transportes v. 23, n. 2. DOI: https://doi.org/10.14295/transportes.v23i2.898.

Bastos, J.B.S.; silva, S.A.T.; Soares, J.B.; Nascimento, L.A.H.; KIM, Y.R. (2016) Triaxial stress sweep test protocol considerations for permanent deformation characterization of asphalt mixtures. RMPD, v. 19, n. 2. DOI: https://doi.org/10.1080/14680629.2016.1261729.

Chalmers, A.F. (2000) 0 que é Ciência afinal? Editora Brasiliense. ISBN: 8511120610.

Feyerabend, P. (1977) Contra o método. Editora Francisco Alves, RJ.

Flexner, A. (1939) The usefulness of useless knowledges. Princeton University Press. ISBN: 9780691174761.

Fritzen, M.A. (2016) Desenvolvimento e validação de função de transferência para previsão de dano por fadiga em pavimentos asfálticos. Tese de Doutorado. Programa de Engenharia Civil/COPPE/UFRJ.

SETRA/LCPC (1978) Guide technique. French Design Manual for Pavement Structures. LCPC et SETRA, Paris.

Lakatos, I. (1979) O falseamento e a metodologia dos programas de pesquisa científica. In: LAKATOS, I. e MUSGRAVE, A. A crítica e o desenvolvimento do conhecimento. São Paulo: Cultrix.

Khun, T.S. (1962) The structure of scientific revolutions. The University of Chicago Press.

Motta, L.M.G. (1991) Método de Dimensionamento de Pavimentos Flexíveis; Critério de Confiabilidade e Ensaios de Cargas Repetidas. Tese de Doutorado, UFRJ.

Motta, L.M.G.; Leite, L.F.M.; Franco, F.A.C.P.; Silva, C.F.S.C.; Medina, J. (2018) Execução de estudos e pesquisa para elaboração de método mecanístico - empírico de dimensionamento de pavimentos asfálticos. Convênio UFRJ/DNIT.

Nascimento, L.A.H. (2015) Implementation and Validation of the Viscoelastic Continuum Damage Theory for Asphalt Mixture and Pavement Analysis in Brazil. PhD Dissertation, North Carolina State University. USA.

Popper (1963) Conjectures and Refutations: The Growth of Scientific Knowledge.

Santiago, L.S.; Babadopulos, L.F.A.L.; Soares, J.B. (2019) Desenvolvimento de Função de Transferência para Previsão de Área Trincada em Pavimentos Asfálticos por Meio da Simulação do Dano por Fadiga Utilizando Modelo S-VECD e Análises Elásticas. Aceito para publicação. Transportes.

Soares, J.B.; Moreno, A.M.; Motta, L.M.G. (2009) Aspectos gerais de métodos de dimensionamento de pavimentos asfálticos de vários países e a relação com um novo método brasileiro. Revista Pavimentação, XVII.

Souza, M.L. (1981) Método de projeto de pavimentos flexíveis. 3ª ed. Rev. e Atual. RJ, IPR (Publ. 667). 